\title{
Photo-Ionic Cells: Two Solutions to Store Solar Energy and Generate Electricity on Demand
}

\author{
Manuel A. Méndez, Pekka Peljo, Micheál D. Scanlon, Heron Vrubel, and Hubert H. Girault* \\ Laboratoire d'Electrochimie Physique et Analytique, Ecole Polytechnique Fédérale de Lausanne, CH-1015 Lausanne, Switzerland
}

Supporting Information

\begin{abstract}
A solar energy conversion concept based on the photoinduced separation of a pair of redox species in a biphasic liquid cell is presented. The redox pair is subsequently discharged in an electrochemical flow cell to generate electricity. To illustrate this generic concept, we have revisited the thionine/cobalt EDTA system where, upon light excitation, the excited thionine dye is quenched in the aqueous solution by the [Co(II)EDTA $]^{2-}$ complex to form both [Co(III)EDTA $]^{-}$and reduced thionine, namely leucothionine, that partitions to the organic phase. As a result, solar energy is converted to a redox pair, leucothionine $/[\mathrm{Co}(\mathrm{III}) \mathrm{EDTA}]^{-}$. The two immiscible liquid phases are separated, and the redox energy is stored in the respective electrolyte solutions. These two solutions can then be electrochemically discharged in a flow cell to generate electricity on demand. The electrode reactions involved are the reoxidation of leucothionine to thionine in the organic solvent and the reduction of the $\mathrm{Co}$ (III) complex in water.
\end{abstract}

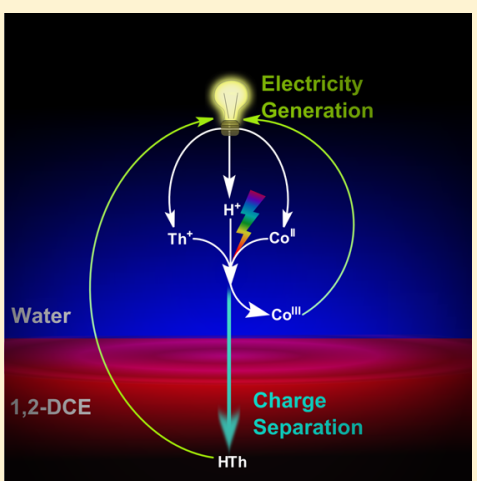

\section{INTRODUCTION}

In the quest for solar electricity, the dry route based on $p / n$ junctions is at present the major route for photovoltaic solar energy conversion. The gist is the presence of an interfacial electric field when two solid semiconductors doped with electron acceptors and donors, respectively, are in contact. The conversion efficiency is theoretically limited by the ShockleyQuiesser limit $^{1}$ at about $30-35 \%$ considering the blackbody radiation, the radiative and nonradiative recombinations, and the spectrum losses associated to the band gap.

An alternative approach is the photoelectrochemical route pioneered in 1839 by Becquerel, where in modern versions an excited sensitizer can inject an electron into a semiconductor electrode, where it diffuses to the back contact. ${ }^{2}$ A redox couple in solution is used to reduce the oxidized dye, thereby resetting it for further photon capture. The oxidized form of the redox couple diffuses in solution to the counter electrode, which is often a platinum based electrode, to be reduced in the dark. ${ }^{3}$ In this special issue dedicated to Prof. Michael Grätzel, many papers are dedicated to the performances of dye sensitized solar cells (DSSC) for which the maximum conversion efficiency stands at about $15 \%$ for perovskite based cells. ${ }^{4}$

An intrinsic characteristic of most photovoltaic systems is their planar architecture and the need of a current collection pattern made of busbars and fingers to collect the current from the light permeable layer. Thus, optimization of such systems is required to achieve a desirable compromise between light exposure and low resistance of the current extractor. ${ }^{5}$

Other electrochemical routes have been proposed to capture solar energy. Chief among these is the photogalvanic approach, where a photoinduced electron transfer reaction occurs not at an electrode but in the bulk of an electrolyte solution sandwiched between two electrodes. ${ }^{6,7}$ In this approach, in the case of a reductive quenching, the reduced sensitizer and the oxidized quencher diffuse to the transparent and the dark electrodes to be oxidized and reduced, respectively. Here, the recombination is avoided mainly by kinetic factors, setting up concentration gradients. Albery and Archer have shown that an optimum efficiency of $18 \%{ }^{8}$ is theoretically possible, albeit never experimentally achieved with most reported systems operating at an efficiency of only a few percent. ${ }^{6,7}$

The purpose of this article is to revisit the concept of charge separation at the interface between two immiscible electrolyte solutions (ITIES). In 1962 (nihil novi sub sole), Rabinowitch et al. showed that photosystems comprising an aqueous dye, such as thionine $\left(\mathrm{Th}^{+}\right)$, and an aqueous redox quencher, such as $\mathrm{Fe}(\mathrm{II})$ (investigated as early as 1940 as a photogalvanic cell ${ }^{9-13}$ and later in microemulsions by Grätzel ${ }^{14,15}$ ), provide charge separation if the reaction is carried out in a biphasic water-ether emulsion. The reduced dye is extracted to the organic phase, while the oxidized quencher remains in the aqueous phase. ${ }^{16}$ In 1970, the same authors showed that if the aqueous redox quencher is $[\text { cobalt(II)EDTA }]^{2-}$, then a $54 \%$ separation of the photoproducts is possible when working at $\mathrm{pH} 7.2 .^{17}$

The concept of photochemical charge separation at a liquidliquid interface was also investigated in the nineties by Kotov and Kuzmin, who published a series of papers where one of the products of a photochemical reaction near a liquid-liquid interface was extracted to the adjacent phase. ${ }^{18-20}$ If the

Special Issue: Michael Grätzel Festschrift

Received: January 14, 2014

Revised: February 27, 2014

Published: February 27, 2014 
transferring photoproduct was an ionic species, then a current could be measured across the soft interface.

In our laboratory, we have studied for many years photoinduced charge separations at polarized ITIES $^{21}$ using heterogeneous photoinduced charge transfer reactions between aqueous sensitizers, such as porphyrins, and lipophilic redox quenchers, such as ferrocene. ${ }^{22-25}$ We have shown that by using supersensitizers such as ferrocyanide in the aqueous phase, we could generate a redox charge storage of ferrocyanide in water and ferricinium in 1,2-dichloroethane (DCE). ${ }^{26}$

More recently, Halls and Wadhawan have presented a photogalvanic cell based on lyotropic liquid crystal layers entrapping a sensitizer. In this lamellar biphasic approach, a $2 \%$ efficiency was demonstrated. ${ }^{27}$

Herein, we present finite element simulations applicable to generic sensitizer $(S)$ /quencher $(\mathrm{Q})$ combinations, and (photo)electrochemical experiments with the original $\mathrm{Th}^{+}$-cobalt EDTA system to evaluate the potential of photoionic cells where charge separation is obtained at a soft polarizable liquidliquid interface. We propose the coupling of a photoionic cell with a flow electrolyzer, thereby realizing a complete photoredox battery.

\section{PHOTOIONIC CELL PRINCIPLE}

In a photoelectronic cell, by contacting a $p$-type and an $n$-type semiconductor, to form a $p \mid n$-junction, the absorption of light by silicon atoms creates an electron-hole pair separated by a gradient of electrochemical potential. The latter drives the charge separation process, as illustrated in Scheme 1. In a photoionic cell

Scheme 1. Charge Separation at a Solid Semiconductor Junction As in a Photovoltaic Solar Cell (Top) and at a Liquid-Liquid Junction As in a Photo-Ionic Solar Cell (Bottom) ${ }^{a}$
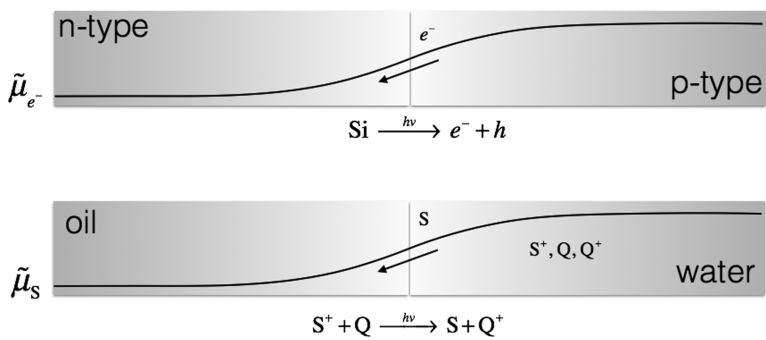

$a_{\tilde{\mu}_{\mathrm{e}}-}$ is the electrochemical potential of the electron and $\tilde{\mu}_{\mathrm{S}}$ the electrochemical potential of the reduced dye.

based on the $\mathrm{Th}^{+}$-cobalt EDTA system, the absorption of light by the sensitizer dye $\left(\mathrm{S}^{+}\right)$and the redox quenching of the excited dye by a quencher $(\mathrm{Q})$ in the same solution results in a charge separation process forming a pair $\left(S-\mathrm{Q}^{+}\right)$for an oxidative quenching. The specificity of a photoionic cell stems from the presence of an electrochemical potential gradient at a liquidliquid interface arising from a difference of solvation energy of the different species, as illustrated in Scheme 1.

In the $\mathrm{Th}^{+}-[\mathrm{Co}(\mathrm{II}) \mathrm{EDTA}]^{2-}$ system, discussed below, the system can be described by a simplified model where an aqueous solution containing the aqueous sensitizer, $\mathrm{S}^{+\mathrm{w}}$, and the reducing quencher, $\mathrm{R}^{\mathrm{w}}$, are mixed or mechanically emulsified with an organic solvent in a photoreactor. Light absorption triggers the following reactions: ${ }^{6}$

$$
\mathrm{S}^{+\mathrm{w}} \stackrel{h \nu}{\rightarrow} \mathrm{S}^{+\mathrm{w}} *
$$

$$
\begin{aligned}
& \mathrm{S}^{+\mathrm{w}} * \mathrm{R}^{\mathrm{w}} \stackrel{k_{\mathrm{q}}}{\rightarrow} \mathrm{S}^{\mathrm{w}}+\mathrm{O}^{\mathrm{w}} \\
& \mathrm{S}^{\mathrm{w}} \stackrel{K_{\mathrm{p}}}{\rightleftarrows} \mathrm{S}^{\mathrm{o}}
\end{aligned}
$$

The first reaction is light absorption, followed by the homogeneous redox quenching of the excited dye, $S^{+w *}$, in water (eq 2) and the extraction of the lipophilic reduced sensitizer, $S$, into the organic phase (eq 3). To maximize the concentration of $\mathrm{S}^{+\mathrm{w}} *$ in eq 1 , it is important to work with high concentrations of strongly absorbing dyes in a cell geometry that allows for a sufficient aqueous layer thickness. To favor eq 2 , it is important to choose a dye with a long excited state lifetime, preferably in the microsecond range, along with a high concentration of quencher. For the extraction to take place, the photoproduct $S$ has to be neutral. The reduced form of $\mathrm{Th}^{+}$, leucothionine ( $\mathrm{HTh})$, is protonated at a $\mathrm{pH}$ below 6, so the $\mathrm{pH}$ has to be higher than the $\mathrm{p} K_{\mathrm{a}}$ of the leucodye. To ensure that the extraction reaction is fast compared to diffusion in solution, the biphasic system should be emulsified to increase the contact area between the two phases, optimize the surface to volume ratio, and reduce the diffusion time of $S$ in the aqueous phase so as to avoid the recombination reaction 4 :

$$
\mathrm{S}^{\mathrm{W}}+\mathrm{O}^{\mathrm{w}} \stackrel{k_{\mathrm{rec}}}{\longrightarrow} \mathrm{S}^{+\mathrm{w}}+\mathrm{R}^{\mathrm{W}}
$$

Additionally, to control the partition of different ionic species at a liquid-liquid interface, it is important to realize that these liquid-liquid interfaces are polarized and that the partition of charged species depends on the Galvani potential difference between the two phases. This is a key aspect of a photoionic cell. For example, if the interface is polarized negatively (water vs oil) by the distribution of a lipophilic cation (vide infra), then the heterogeneous back reaction 5 is not favored.

$$
\mathrm{S}^{\mathrm{o}}+\mathrm{O}^{\mathrm{w}} \rightarrow \mathrm{S}^{+\mathrm{w}}+\mathrm{R}^{\mathrm{w}}
$$

Next, the two immiscible solutions are separated at the exit of the photoionic cell. The aqueous phase contains the oxidized quencher, $\mathrm{O}^{\mathrm{w}}$, and the organic phase the reduced sensitizer, $\mathrm{S}^{\mathrm{o}}$. After this physical separation of the two phases, the heterogeneous back reaction 5 is no longer possible and the photoenergy effectively stored as redox energy. As such, a photoionic cell produces "redox solar fuels" that can be stored.

The mechanism presented above is simply one of many possible permutations. Indeed, one can imagine processes where the quencher rather than the sensitizer is extracted to the organic phase. Also, one can imagine heterogeneous quenching processes using supersensitizers. From an engineering viewpoint, there are many possible strategies to design a photoionic cell and similarities to approaches used for solvent extraction processes are inevitable. Basically, the basis of a photoionic cell can be achieved by dispersing light absorbing aqueous microdroplets, generated by a transparent polymer or glass column with sieve plates or shower heads, in a nonlight-absorbing organic phase. This is a major advantage compared to other photovoltaic systems that require costly large glass flat panels.

In the final step, the two solutions generated in the photoionic cell are passed through a flow cell releasing the redox energy as electricity. The reactions are:

$$
\begin{aligned}
& \mathrm{S}^{\mathrm{o}} \rightarrow \mathrm{S}^{+\mathrm{w}}+e^{-} \\
& \mathrm{O}^{\mathrm{w}}+e^{-} \rightarrow \mathrm{R}^{\mathrm{w}}
\end{aligned}
$$

Indeed, upon oxidation, the sensitizer transfers back to the aqueous phase, resetting the reactants for further reactions. 
The coupling of the photoionic cell with a flow cell forms a photoredox battery, as illustrated in Scheme 2, for the $\mathrm{Th}^{+} /$

\section{Scheme 2. Biphasic Photo-Redox Battery ${ }^{a}$}

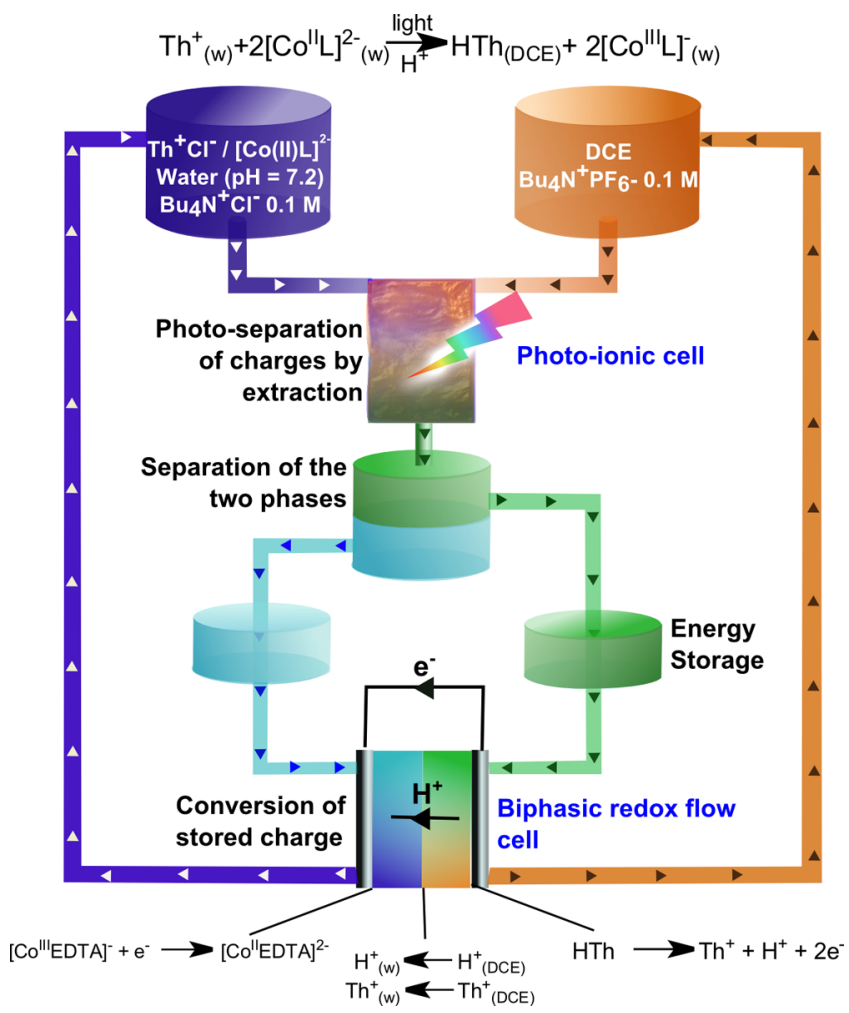

${ }^{a}$ The aqueous and the organic phases are mixed in the photoionic cell, then separated and stored. The stored electrochemical energy is subsequently converted to electricity in a flow battery.

cobalt-EDTA system originally proposed by Rabinowitch et al. $^{16,17}$ The formal redox potential of the $[\mathrm{Co}(\mathrm{II}) \mathrm{EDTA}]^{2-}$ / $[\mathrm{Co}(\mathrm{III}) \mathrm{EDTA}]^{-}$couple is $0.37-0.38 \mathrm{~V}$ vs SHE, ${ }^{28,29}$ and the formal redox potential of $\mathrm{Th}^{+}$is ca. $0.056 \mathrm{~V}$ vs $\mathrm{SHE}^{29}$ at $\mathrm{pH} 7$ (or $0.057 \mathrm{~V}$ vs SHE at $\mathrm{pH} 7.2$, vide infra). Thus, the expected cell voltage of the photoredox battery would be ca. $0.32 \mathrm{~V}$. As the transfer energy of $\mathrm{Th}^{+}$into the oil phase is close to zero (vide infra), the redox potential of $\mathrm{Th}^{+}$in DCE vs aqueous SHE does not significantly differ from the value in water.

A photoredox battery has the unique ability to convert solar energy into "redox fuels" that need only be consumed when required to generate electricity to meet specific demand. This is a major advantage compared to solar energy conversion by classical photovoltaic systems that are coupled to, and reliant on, an electric grid to immediately distribute the produced electricity, irrespective of demand.

Another major advantage of a photoionic cell is its ease of coupling with classical low or medium temperature solar thermal panels. The energy loss of a photoionic cell is mainly heat that is thus available for exploitation. In addition, passive thermosiphon pumping can be envisaged.

\section{EXPERIMENTAL SECTION}

3.1. Chemicals. All chemicals were used as received. All aqueous solutions were prepared with ultrapure water (Millipore Milli-Q specific resistivity $18.2 \mathrm{M} \Omega \cdot \mathrm{cm}$ ). Thionine chloride ( ThCl) was purchased from Roth AG. Tetrabutylammonium chloride (TBACl), tetrabutlammonium hexafluorophosphate
$\left(\mathrm{TBAPF}_{6}\right)$, tetramethylammonium chloride (TMACl), sodium hydrogen phosphate, sodium dihydrogenphosphate, and 1,2dichloroethane (DCE, >99.8\%) were ordered from Fluka. Potassium cobalt(III) EDTA (K[Co(III)(EDTA)]) was synthesized according to the literature procedures. ${ }^{30} \mathrm{~K}_{2}[\mathrm{Co}(\mathrm{II})$ (EDTA)] was prepared by a modification of the method used by Dwyer et al. ${ }^{30}$ for the synthesis of $\mathrm{K}[\mathrm{Co}(\mathrm{III})(\mathrm{EDTA})]$. Solid $\mathrm{K}_{2}[\mathrm{Co}(\mathrm{II})(\mathrm{EDTA})]$ was precipitated out of the solution by addition of ethanol.

Lithium tetrakis(pentafluorophenyl)borate (LiTB) n-etherate (Boulder Scientific Company) and bis (triphenylphosphoranylidene) ammonium chloride (BACl, $97 \%$, Aldrich) were used to prepare bis(triphenylphosphoranylidene) ammonium tetrakis(pentafluorophenyl)borate (BATB) by metathesis of aqueous equimolar solutions of $\mathrm{BACl}$ and LiTB. The resulting precipitates were filtered, washed, and recrystallized from an acetone: ethanol (1:1) mixture. ${ }^{31}$

Leucothionine (HTh) was synthesized via a potentialcontrolled electrolysis at $-0.45 \mathrm{~V}$ vs $\mathrm{Ag} / \mathrm{AgCl}$ at $\mathrm{pH} 7.2$ in an $\mathrm{H}$-cell with two high surface area vitreous carbon electrodes from a saturated $\mathrm{Th}^{+}$solution in a phosphate buffer.

3.2. Electrochemical Measurements. Ion-transfer voltammetry experiments at the water-DCE interface in a fourelectrode configuration and classical voltammetry with a threeelectrode configuration were all performed using a PGSTAT 30 potentiostat (Metrohm, $\mathrm{CH}$ ). For ion-transfer voltammetry, two platinum counter electrodes were positioned in the aqueous and organic phases, respectively, to supply the current flow. Silver/ silver chloride $(\mathrm{Ag} / \mathrm{AgCl})$ reference electrodes were connected to the aqueous and organic phases, respectively, via Luggin capillaries. The Galvani potential difference across the interface $\left(\Delta_{\mathrm{o}}^{\mathrm{w}} \phi\right)$ was estimated by taking the standard ion transfer potential of tetramethylammonium cation $\left(\mathrm{TMA}^{+}\right)$as $0.160 \mathrm{~V}^{32}$ The half-wave potential of $\mathrm{TMA}^{+}$transfer was estimated as 0.13 $\mathrm{V}$ based on the correction of ionic activities by Debye-Hückel theory as described in ref 32 . No $i R$ compensation was applied to the cell. The area of the liquid-liquid interface was $1.53 \mathrm{~cm}^{2}$. The electrochemical cell configuration for ion transfer voltammetry experiments is shown in Scheme 3A.

3.3. Spectroscopic Measurements. A quartz cell with an optical path length of $1 \mathrm{~cm}$ was used. An Ocean Optics spectrophotometer was used together with halogen and deuterium lamps as light sources. All spectroscopic measurements were performed in a nitrogen-filled glovebox. For spectroelectrochemical measurements, spectral monitoring of the electrochemical reduction of $\mathrm{Th}^{+}$using a thin platinum mesh electrode placed into a $1 \mathrm{~mm}$ optical path quartz cuvette was performed. UV-visible spectra were acquired as a function of potential from 0 to $-0.27 \mathrm{~V}$ vs $\mathrm{Ag} / \mathrm{AgCl}$ for a solution $0.022 \mathrm{mM}$ in $\mathrm{ThCl}$ in $50 \mathrm{mM}$ phosphate buffer $(\mathrm{pH}=7.2)$ in potential steps of $30 \mathrm{mV}$.

3.4. Photoextraction Experiments and Discharge Experiments. Solutions of $\mathrm{ThCl}$ (filtered saturated solutions) were prepared with carefully deoxygenated $50 \mathrm{mM}$ phosphate buffer ( $\mathrm{pH} 7.2)$ in a nitrogen filled glovebox. Then $15 \mathrm{~mL}$ of $\mathrm{ThCl}$ solution was introduced into the photoreaction cell and the cell was filled with carefully deoxygenated DCE (20 to $25 \mathrm{~mL}$ ) in the glovebox. The contents of the cell were emulsified with a magnetic stirrer, and the cell was illuminated through an optical window from above with a $532 \mathrm{~nm}$ LED light (power of $55 \mathrm{~mW}$, Thorlabs). The phases were separated in the glovebox and analyzed before and after illumination by UV-vis. The cell 
Scheme 3. Cell Configurations for (A) Ion-Transfer Voltammetry, (B) Light Activated Charging of the PhotoIonic Cell, (C) Discharge of the Cell Presented in (B) after Irradiation, and (D) Discharge of the Chemically Prepared Photo-Products

(A)

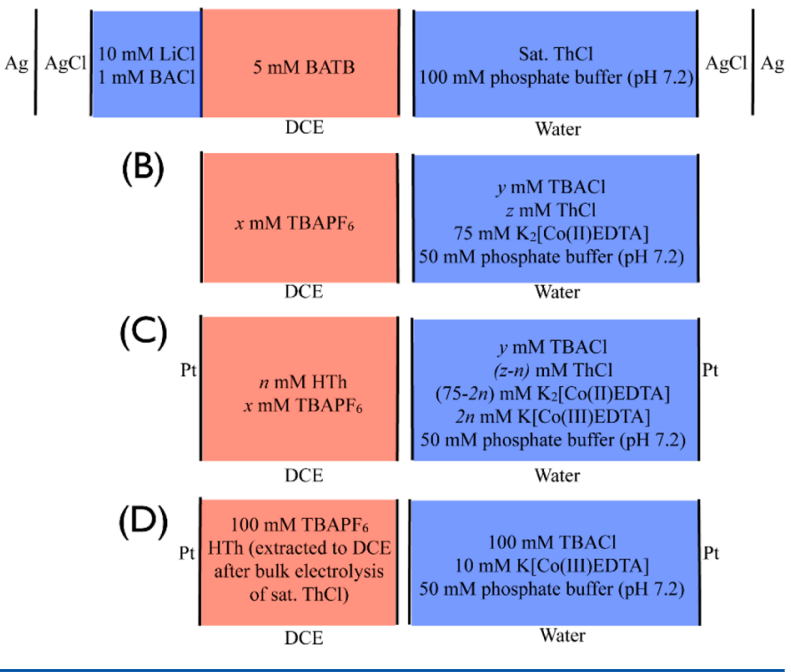

configuration of the biphasic photoionic cell prior to photoextraction and charging is illustrated in Scheme 3B.

The two immiscible phases, collected under an inert atmosphere from an operational photoionic cell, were introduced into an electrochemical cell and a platinum wire $(\mathrm{ca} .1 \mathrm{~cm})$ was placed in each phase. The cell configuration of the biphasic photoionic cell after photoextraction and charging, and thus ready for discharge, is illustrated in Scheme 3C. For comparison, the discharge behavior of a fully charged cell was studied in an aqueous phosphate buffer solution $(\mathrm{pH}=7.2)$ containing chemically prepared $10 \mathrm{mM}$ [Co(III)EDTA $]^{-}$and $100 \mathrm{mM}$ $\mathrm{TBACl}$ and an organic phase containing HTh (produced by bulk electrolysis from a saturated $\mathrm{Th}^{+}$solution and extracted to DCE) and $100 \mathrm{mM} \mathrm{TBAPF}_{6}$. The cell configuration for the discharge of the latter cell is illustrated in Scheme 3D. The platinum wires had to be very carefully cleaned to avoid any contamination from adsorbed species or polythionine from previous experiments. During the discharge experiments, the oil phase was gently stirred to favor mass transport across the interface. However, the stirring rate was always kept low enough in such a way that the upper aqueous phase did not come into contact with the electrode immersed in the bottom organic phase.

\section{RESULTS AND DISCUSSION}

4.1. Finite Element Simulation. The model used to study the efficiency of the photoionic cell and extraction of the reduced dye is based on the work of Albery et al. ${ }^{8} \mathrm{Th}^{+}$absorbs light and is excited, as described by eq 1 . The excited state reacts with electron donors to give colorless leucodye (eq 2). The governing equations for the system are presented in the Supporting Information (SI). The suggested mechanism for the $\mathrm{Th}^{+}-$ quencher system is actually more complicated than described in eqs 1-3: in the case of the $\mathrm{Th}^{+}$-iron system, the photoreaction with $\mathrm{Th}^{+}$and $\mathrm{Fe}$ (II) first produces semithionine and $\mathrm{Fe}$ (III). Semithionine quickly disproportionates to form $\mathrm{Th}^{+}$and $\mathrm{HTh}^{33}$ The reactions with $[\mathrm{Co}(\mathrm{II})(\mathrm{EDTA})]^{2-}$ are expected to happen similarly. However, as the system has not been studied in nonacidic media, the simulations of the more complicated mechanism would include multiple unknown parameters. Hence a simplified model was chosen for this study.

The model was validated by first reproducing the calculations for a 1D-thin layer photogalvanic concentration cell (see the SI for further details). ${ }^{34}$ To simulate a photoionic cell, the organic phase was added to the model as a second layer and the partition of the neutral species was introduced as a flux boundary condition as shown in Scheme 4. The effect of the flow parallel to

Scheme 4. Schematic Model System to Evaluate the Extraction Efficiency of $S$ in the Organic Phas ${ }^{a}$

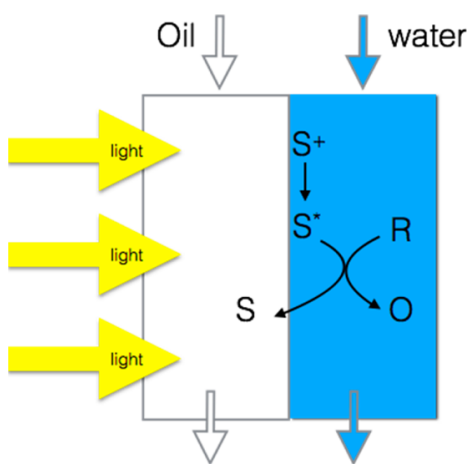

${ }^{a}$ Phases are separated at the outlet. The arrows illustrate the flowing biphasic system.

the interface on the extraction efficiency was studied by extending the model to 2D. The effects of the flow were studied by adding a parabolic flow at the inlet. Results of the $2 \mathrm{D}$ model without the flow were identical to the $1 \mathrm{D}$ simulations. When the flow was introduced into the model, validation was carried out by refining the mesh until the results were repeatable.

4.1.1. Static Biphasic System. To gain a physical insight into the characteristics of photoionic cells, we decided not to simulate emulsions, as studied experimentally herein, but to use a model system made of two layers of solvent. The thickness of both phases was set at $1 \mathrm{~mm}$. The DCE phase was at the negative $x$-axis and water at the positive $x$-axis. The initial parameters for the rate constants $\left(k_{\mathrm{q}}=6.7 \times 10^{9} \mathrm{M}^{-1} \mathrm{~s}^{-1}\right.$ and $\left.k_{\mathrm{rec}}=3 \times 10^{5} \mathrm{M}^{-1} \mathrm{~s}^{-1}\right)$ and for the lifetime of the triplet state $(16 \mu \mathrm{s})$ were taken from the paper of Harriman et al. for the iron- $\mathrm{Th}^{+}$system. ${ }^{33}$ There was no available data for the $\mathrm{Th}^{+}$system in neutral $\mathrm{pH}$, or with $[\mathrm{Co}(\mathrm{II}) \mathrm{EDTA}]^{2-}$. Hence the experimental conditions of ref 17 $\left(\mathrm{Th}^{+}\right.$concentration of $19.65 \mu \mathrm{M},[\mathrm{Co}(\mathrm{II}) \mathrm{EDTA}]^{2-}$ concentration of $1.018 \mathrm{mM}, \mathrm{pH} 7.2$ ), where the partition coefficient $\left(K_{\mathrm{p}}\right)$ of HTh between ether and water was determined as 1.63, were used to estimate the rates of $k_{\mathrm{q}}$ and $k_{\text {rec }}$. The rates of the photoreactions were adjusted to $k_{\mathrm{q}}=1 \times 10^{7} \mathrm{M}^{-1} \mathrm{~s}^{-1}$ and $k_{\text {rec }}=3$ $\times 10^{4} \mathrm{M}^{-1} \mathrm{~s}^{-1}$ in the simulations to obtain the experimental value of $54.4 \% .{ }^{17}$ The extraction efficiency is defined as the steady state concentration of reduced dye in the organic phase divided by the initial concentration of the dye in the aqueous solution. The phase volume ratio was $1: 1$.

The effect of different parameters, primarily (i) those that influence the kinetics, i.e., the quenching rate, $k_{\mathrm{q}}$, and the recombination rate, $k_{\text {rec }}$ (ii) the concentrations of the oxidized sensitizer $\left(\mathrm{S}^{+}\right.$, i.e., $\left.\mathrm{Th}^{+}\right)$and the reduced quencher $(\mathrm{R}$, i.e., $[\mathrm{Co}(\mathrm{II}) \mathrm{EDTA}]^{2-}$ ) initially present in the aqueous phase, (iii) the efficiency with which the reduced neutral sensitizer (S, i.e., HTh) can partition to the oil phase $\left(K_{\mathrm{p}}\right)$, (iv) the intensity of the light incident on the photoionic cell $\left(I_{0}\right)$, and $(v)$ the lifetime of the sensitizer excited state, on the steady state extraction efficiency 
were investigated (for a summary of the different permutations of the different parameters see Table 1).

\section{Table 1. Effects of Different Parameters for the Extraction Efficiency for the Rabinowitch System ${ }^{17}$ (Amount of Extracted HTh Divided by the Initial Amount of the Dye) in the Static Photo-Ionic Cell ${ }^{a}$}

\begin{tabular}{|c|c|c|c|c|c|}
\hline \multicolumn{6}{|c|}{ effect of $k_{\text {rec }}$} \\
\hline \multicolumn{2}{|c|}{$k_{\mathrm{rec}}\left(\mathrm{M}^{-1} \mathrm{~s}^{-1}\right)$} & $K_{\text {photo }} \quad I$ & $K_{\mathrm{q}}\left(\mathrm{M}^{-1} \mathrm{~s}^{-1}\right)$ & $c_{\mathrm{R}} / c_{\mathrm{Th}}$ & extraction efficiency (\%) \\
\hline \multicolumn{2}{|c|}{$3 \times 10^{4}$} & 333 & $10^{7}$ & 51.8 & 54.4 \\
\hline \multicolumn{2}{|c|}{$3 \times 10^{3}$} & & $10^{6}$ & & 55.1 \\
\hline \multicolumn{2}{|c|}{$3 \times 10^{5}$} & & $10^{8}$ & & 48.4 \\
\hline \multicolumn{2}{|c|}{$3 \times 10^{6}$} & & $10^{9}$ & & 29.5 \\
\hline \multicolumn{2}{|c|}{$2 \times 10^{6}$} & & & & 33.4 \\
\hline \multicolumn{2}{|c|}{$1 \times 10^{6}$} & & & & 40.9 \\
\hline \multicolumn{2}{|c|}{$5 \times 10^{5}$} & & & & 47.7 \\
\hline \multicolumn{2}{|c|}{$2 \times 10^{5}$} & & & & 54.5 \\
\hline \multicolumn{6}{|c|}{ effect of the concentrations of $\mathrm{R}$ and $\mathrm{Th}^{+}$} \\
\hline $\begin{array}{c}c_{\mathrm{R}} \\
(\mathrm{mM})\end{array}$ & $\begin{array}{c}c_{\mathrm{Th}} \\
(\mathrm{mM})\end{array}$ & $K_{\text {photo }}$ & $\quad \begin{array}{c}K_{\mathrm{q}} \\
\left(\mathrm{M}^{-1} \mathrm{~s}^{-1}\right)\end{array}$ & $c_{\mathrm{R}} / c_{\mathrm{Th}}$ & extraction efficiency (\%) \\
\hline \multirow{2}{*}{$\begin{array}{c}1.02 \\
10\end{array}$} & 0.02 & 333 & $10^{7}$ & 51.8 & 54.4 \\
\hline & 0.02 & & & 509 & 59.9 \\
\hline 50 & 0.02 & & & 2544 & 60.5 \\
\hline \multirow{2}{*}{$\begin{array}{l}100 \\
100\end{array}$} & 0.02 & & & 5090 & 60.6 \\
\hline & 0.1 & & & 1000 & 56 \\
\hline $\begin{array}{l}100 \\
500\end{array}$ & 0.1 & & & 5000 & 56.2 \\
\hline \multirow[t]{2}{*}{5000} & 1 & & & 5000 & 39.4 \\
\hline & & & effect of $K_{\mathrm{p}} \mathrm{f}$ & for HTh & \\
\hline$K_{\mathrm{p}}$ & $K_{\text {photo }}$ & $K_{\mathrm{q}}($ & $\left(\mathrm{M}^{-1} \mathrm{~s}^{-1}\right)$ & $c_{\mathrm{R}} / c_{\mathrm{Th}}$ & extraction efficiency (\%) \\
\hline \multirow{2}{*}{$\begin{array}{c}1.63 \\
5\end{array}$} & 333 & & $10^{7}$ & 51.8 & 54.4 \\
\hline & & & & 1000 & 79.4 \\
\hline \multicolumn{2}{|l|}{10} & & & & 88.5 \\
\hline \multicolumn{2}{|l|}{100} & & & & 98.7 \\
\hline \multicolumn{2}{|l|}{1000} & & & & 99.9 \\
\hline \multirow[b]{2}{*}{$\tau(\mu \mathrm{s})$} & & effect & ct of the excitec & d state lifet & ime \\
\hline & $K_{\text {photo }}$ & $K_{\mathrm{q}}($ & $\left(\mathrm{M}^{-1} \mathrm{~s}^{-1}\right)$ & $c_{\mathrm{R}} / c_{\mathrm{Th}}$ & extraction efficiency (\%) \\
\hline 1 & 333 & & $10^{7}$ & 50 & 29.7 \\
\hline 5 & & & & & 46.2 \\
\hline 16 & & & & & 54.4 \\
\hline 50 & & & & & 58.4 \\
\hline
\end{tabular}

${ }^{a}$ Parameter values in bold represent the initial conditions for the simulation.

If the ratio between the quenching rate $k_{\mathrm{q}}$ (initial value $1 \times 10^{7}$ $\mathrm{M}^{-1} \mathrm{~s}^{-1}$ ) and the recombination rate $k_{\text {rec }}$ (initial value $3 \times 10^{4}$ $\left.\mathrm{M}^{-1} \mathrm{~s}^{-1}\right)$ remained the same $\left(K_{\text {photo }}=k_{\mathrm{q}} / k_{\mathrm{rec}}=333\right)$ but the reaction rates were decreased by 1 order of magnitude, then the extraction slightly increased to $55.1 \%$ from $54.4 \%$. Further decreasing the reaction rates only increased the extraction efficiency slightly to $55.2 \%$. Conversely, an increase of 1 or 2 orders of magnitude causes the extraction efficiency to decrease to 48.4 and $29.5 \%$, respectively

Increasing the concentration of $[\mathrm{Co}(\mathrm{II}) \mathrm{EDTA}]^{2-}$ from $1 \mathrm{mM}$ to 10 or $100 \mathrm{mM}$ increased the extraction efficiency to $59.9 \%$ and $60.6 \%$, respectively. If the concentration of $\mathrm{Th}^{+}$was increased to $0.1 \mathrm{mM}$ (initial value $19.6 \mu \mathrm{M}$ ) and the concentration of $[\mathrm{Co}(\mathrm{II}) \mathrm{EDTA}]^{2-}$ was kept 1000 times higher, the extraction efficiency decreased from $60.6 \%$ to $56.0 \%$. Further increasing the $\mathrm{Th}^{+}$concentration to $1 \mathrm{mM}$ (with $5 \mathrm{M}[\mathrm{Co}(\mathrm{II}) \mathrm{EDTA}]^{2-}$ ) decreased the extraction efficiency to $39.4 \%$, due to the small partition coefficient of the leucodye. The presence of a larger concentration of sensitizer meant that all the light was absorbed very close to the interface and, thus, at equilibrium the oil phase could no longer extract the neutral dye at a rate in excess of that with which the recombination reaction was consuming it. However, if the partition coefficient was increased to $100,96.3 \%$ extraction was achieved. Additionally, if the intensity of light was increased 10-fold, the extraction increased to $56.4 \%$ from $39.4 \%$ $\left.(1 \mathrm{mM} \text { Th, } 5 \mathrm{M} \text { [Co(II)EDTA }]^{2-}, K=1.63\right)$. Also, as expected, an increase in $K_{\text {photo }}$ values also induces a significant increase in the extraction efficiency.

If the partition coefficient of the neutral dye was increased from $1.63\left(0.1 \mathrm{mM} \mathrm{Th}^{+}, 100 \mathrm{mM}[\mathrm{Co}(\mathrm{II}) \mathrm{EDTA}]^{2-}\right)$ to 2,10 , 100 , and 1000, the resulting extraction efficiencies increased stepwise from $56.0 \%$ to $60.9 \%$ to $88.5 \%$, respectively, and then plateaued at $99.9 \%$. If the lifetime of the triplet state was decreased from 16 to $1 \mu \mathrm{s}$, the extraction efficiency decreased from $54.4 \%$ to $29.7 \%$. However, if the partition coefficient was increased to 10 (initial value of 1.63 ), 65.3\% extraction efficiency was observed and further increasing the partition coefficient to 100 increased the extraction efficiency to $93.7 \%$. Hence, we can conclude that the partition coefficient of the neutral dye is one of the most important parameters and should be preferably greater than 10 and optimally greater than 100 . Also, the lifetime of the excited state should be on the order of microseconds. Finally, the concentration of $[\mathrm{Co}(\mathrm{II}) \mathrm{EDTA}]^{2-}$ should be high enough to allow a high rate of quenching, although this parameter is not as influential as the others on the extraction efficiencies.

Figure 1 shows the transient equilibration of the system where light is passing through a layer of DCE phase to impact an aqueous layer, with the model parameters shown in Table 2 . The simulation reproduced our experimental conditions, where the volume ratio between the oil and aqueous phase was $20 \mathrm{~mL}: 15$ $\mathrm{mL}$. The light intensity was set as $1.57 \mathrm{mmol}$ of photons per square meter per second $\left(\mathrm{mmol} \mathrm{m}^{-2} \mathrm{~s}^{-1}\right)$, corresponding to the number of photons of wavelengths less than $700 \mathrm{~nm}$ in AM2 solar radiance. ${ }^{8}$ Nonzero values were used for initial concentrations for numerical stability.

The simulations show that the dye is converted to the leucodye very quickly, in less than $1 \mathrm{~s}$, and the diffusion of the neutral dye into the oil phase is the rate-limiting step of the overall process. Thus, as it can be seen from Figure 1B, appreciable concentrations of the neutral dye in the organic phase start being observed at times beyond $1 \mathrm{~s}$, even if the photoconversion process in the aqueous phase has proceeded almost to completion within the same time scale. The normalized HTh concentration in the oil phase reaches 0.71 , so by taking into account the phase ratio an extraction of $86.9 \%$ is reached. This value is higher than the experimental value of $76 \%$, probably because our model does not include the formation of semithionine followed by its disproportionation into $\mathrm{Th}^{+}$and HTh.

On the basis of these results, a simple batch photoionic cell for storing solar energy could be envisaged: a large tank placed under sunlight slowly converts aqueous $\mathrm{Th}^{+}$into $\mathrm{HTh}$, which partitions to the oil phase. Although the efficiency of the system will not be very high, the system would be a simple way of generating electricity and heat from sunlight. When electricity is needed, the cell can be discharged electrochemically. To optimize the electricity production in a non-emulsified system, the interface must be irradiated from the oil side by ensuring sunlight goes through the oil phase to avoid considerable loss of the photogenerated dye through recombination. Additionally, a 

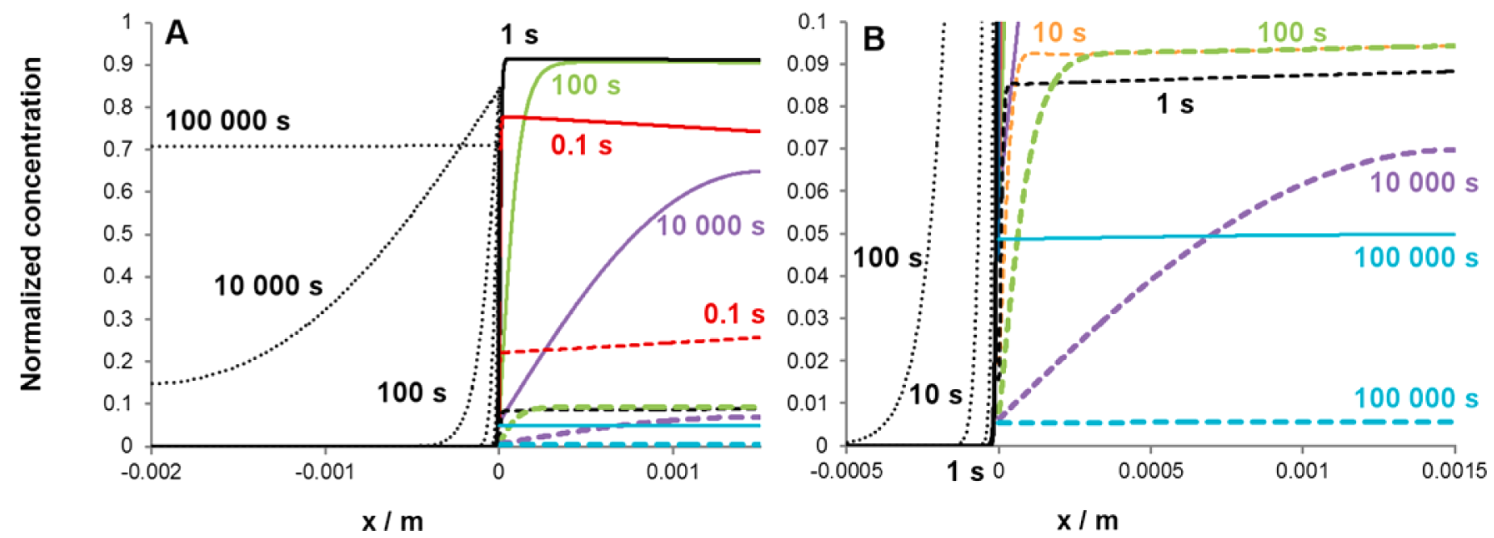

Figure 1. (A) Normalized concentration profiles of the neutral dye (S) in the oil phase (dashed black lines), of $S$ in the aqueous phase (full colored lines) and the cationic dye $\left(\mathrm{S}^{+}\right)$in the aqueous phase (dashed colored lines) at different times. (B) More detailed concentration profiles in the aqueous phase. The concentrations were normalized by the initial thionine $\left(\mathrm{Th}^{+}\right)$concentration in the aqueous phase. DCE phase at negative $x$ values, aqueous phase at positive side. The parameters for the different constants used in the simulation are given in the Table 2

Table 2. Parameters Used in the Simulations in Figure 1

\begin{tabular}{|c|c|c|}
\hline name & expression & description \\
\hline$\varepsilon\left(\mathrm{M}^{-1} \mathrm{~cm}^{-1}\right)$ & $6.5 \times 10^{4}$ & extinction coefficient of the dye $\mathrm{e}^{35}$ \\
\hline$I_{0}\left(\mathrm{~mol} \mathrm{~m}^{-2} \mathrm{~s}^{-1}\right)$ & $1.57 \times 10^{3}$ & $\begin{array}{l}\text { light intensity from AM2 solar radiation } \\
(<700 \mathrm{~nm})^{8}\end{array}$ \\
\hline$S_{0}^{+}(\mathrm{M})$ & $3.5 \times 10^{-5}$ & $\begin{array}{l}\text { initial dye concentration in the aqueous } \\
\text { phase }\end{array}$ \\
\hline$S_{0}(\mathrm{nM})$ & 1 & $\begin{array}{l}\text { initial reduced dye concentration in the } \\
\text { aqueous phase }\end{array}$ \\
\hline$R_{0}(\mathrm{mM})$ & 75 & concentration of reduced quencher species \\
\hline$O_{0}(\mathrm{nM})$ & 1 & concentration of oxidized quencher species \\
\hline$\tau(\mathrm{s})$ & $16 \times 10^{-6}$ & lifetime of the excited state of the dye $\mathrm{e}^{33}$ \\
\hline K & 14.6 & $\begin{array}{l}\text { experimental partition coefficient of the dye } \\
\text { (vide infra) }\end{array}$ \\
\hline$k_{\mathrm{f}}$ & $k_{\mathrm{b}} \times K$ & rate of transfer to oil \\
\hline$k_{\mathrm{b}}\left(\mathrm{m} \mathrm{s}^{-1}\right)$ & 1 & rate of transfer to water \\
\hline$k_{\text {rec }}\left(\mathrm{M}^{-1} \mathrm{~s}^{-1}\right)$ & $3 \times 10^{4}$ & recombination rate \\
\hline$k_{\mathrm{q}}\left(\mathrm{M}^{-1} \mathrm{~s}^{-1}\right)$ & $1 \times 10^{7}$ & quenching rate \\
\hline $\begin{array}{l}D_{\text {CoEDTA }} \\
\left(\mathrm{cm}^{2} \mathrm{~s}^{-1}\right)\end{array}$ & $5.35 \times 10^{-6}$ & $\begin{array}{l}\text { diffusion coefficient of }[\mathrm{Co}(\mathrm{II}) \mathrm{EDTA}]^{2-} \text { at } \\
\mathrm{pH} 7^{36}\end{array}$ \\
\hline$D_{\mathrm{Th}}\left(\mathrm{cm}^{2} \mathrm{~s}^{-1}\right)$ & $5.73 \times 10^{-7}$ & $\begin{array}{l}\text { diffusion coefficient of } \mathrm{Th}^{+} \text {at } \mathrm{pH} 7 \text { (value in } \\
\left.\mathrm{D}_{2} \mathrm{O}\right)^{37}\end{array}$ \\
\hline
\end{tabular}

system based on mixed dyes could be used to take advantage of the full spectrum of sunlight.

4.1.2. Flowing Biphasic System. To investigate how the system would behave in a flow cell, a laminar flow through a thin layer cell under illumination through the oil phase was investigated, as shown in Scheme 4. The cell was $1 \mathrm{~mm}$ thick and $1 \mathrm{~cm}$ long. Both phases were immediately separated after exiting the cell. The model parameters were the same as shown in Table 2, with the exceptions that $\varepsilon=7.15 \times 10^{4} \mathrm{M}^{-1} \mathrm{~cm}^{-1}, c_{\mathrm{R}}=$ $100 \mathrm{mM}, k_{\mathrm{q}}=1 \times 10^{6} \mathrm{M}^{-1} \mathrm{~s}^{-1}$, and $k_{\text {rec }}=1000 \mathrm{M}^{-1} \mathrm{~s}^{-1}$. Also, a diffusion coefficient of $1 \times 10^{-9} \mathrm{~m}^{2} \mathrm{~s}^{-1}$ was used for all species. The simulated steady state concentrations and light flux in the cell are shown in Figure 2. The inlet concentration of $\mathrm{Th}^{+}$in the aqueous phase was $1 \mathrm{mM}$, and the light flux through the oil phase was $1 \mathrm{mmol} \mathrm{m}^{-2} \mathrm{~s}^{-1}$. Both the DCE and aqueous phases move through the cell with the flow profile shown by the arrows and with an average flow rate of $0.01 \mathrm{~m} \mathrm{~s}^{-1}$. The sensitivity of the ratio of the flux of the neutral dye in the oil phase at the outlet and the flux of photons to different parameters was simulated, and the results are shown in Table 3.

The simulation results show that neutral dye does not have time to diffuse deep into the oil phase. In the simulations the incoming light from the left passes through the DCE phase and is absorbed by $\mathrm{Th}^{+}$at the top of the cell. However, due to the low $\mathrm{Th}^{+}$concentration $(1 \mathrm{mM})$, the aqueous phase bleaches and allows for more than $40 \%$ of the incident light to go through at the bottom of the cell. At the inlet, $76.4 \%$ of the $\mathrm{Th}^{+}$is converted to the colorless leucoform of the dye, but only $8.5 \%$ of it is extracted into the oil phase. Hence, most of the light energy is not stored, either leaving the cell undisturbed or being converted to heat in the recombination reaction 5 at the outlet of the cell.

The results show that at low dye concentrations almost all the dye is converted into the neutral form and the aqueous phase bleaches. Under such conditions, most of the incoming light goes through the cell, leading to very low photon-to-product conversion. At the same time, because the photoreaction occurs in the whole volume of the aqueous phase, the extraction efficiency dramatically decreases, as most of the neutral dye has no time to diffuse into the organic phase, and exits the cell with the aqueous flow. After the separation of the phases in the cell outlet all the remaining neutral dye in the aqueous phase is converted back to $\mathrm{Th}^{+}$by the recombination reaction (eq 4). For these two reasons, the conversion of photons to neutral dye in the oil phase becomes very inefficient. Increasing the dye concentration also increases the concentration of the neutral dye in the oil phase, the extraction efficiency, and the conversion of photons to product. This latter effect arises as all of the incoming light is absorbed very close to the liquid-liquid interface, and so the majority of the dye molecules, present away from the interface in the bulk, are unaware of the incoming photons and, thus, not photoactivated. However, all of the photoproduced neutral dye is generated close to the interface, being able to diffuse and transfer into the oil phase before either the recombination reaction or the separation of both phases at the outlet of the cell take place. This leads to higher extraction efficiencies and higher conversion of photons to products.

Importantly, we can also conclude that the partition coefficient $K_{\mathrm{p}}$ is proportional to all of the efficiency values reported in Table 2. However, its effect reaches saturation for $K_{\mathrm{p}}$ values beyond $10^{3}$ and indicates that at $K_{\mathrm{p}}$ values larger than 100 the transfer of neutral dye becomes diffusion controlled. Additional studies on the effect of flow rate with less refined mesh indicate that an increase of the flow rate increases the conversion of photons to product but decreases the neutral dye concentration at the outlet.

Hence for an efficient conversion of photons to product, the photoreaction should preferably take place very close to the 

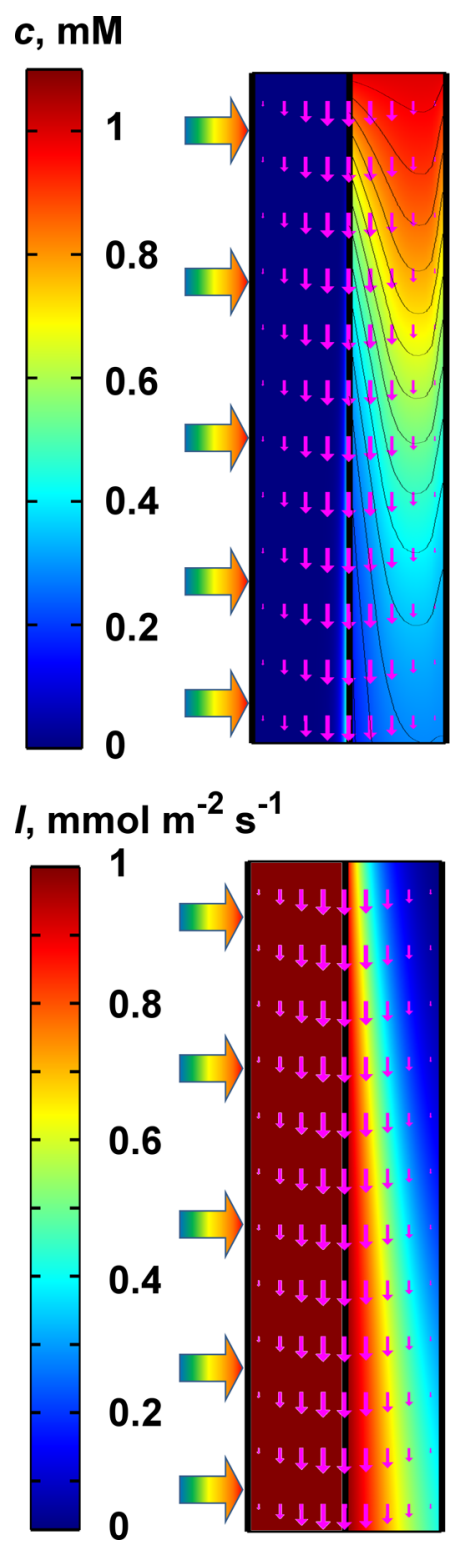

Figure 2. (Top) Steady-state concentration distribution of thionine $\left(\mathrm{Th}^{+}\right)$in the aqueous phase and leucothionine (HTh) in the oil phase during operation of the photoionic cell. The inlet concentration of $\mathrm{Th}^{+}$ in the aqueous phase was set at $1 \mathrm{mM}$. The aqueous phase is shown on the right (thickness of $0.5 \mathrm{~mm}$ ), and the DCE phase is shown on the left (same thickness). (Bottom) Photon flux through the cell (initial photon flux through the DCE phase was set at $1 \mathrm{mmol} \mathrm{m}^{-2} \mathrm{~s}^{-1}$ ) coming from the left and shows that no light passes through the cell at the top but ca. $40 \%$ goes though at the bottom. The length of the cell was $1 \mathrm{~cm}$.

liquid-liquid interface, to avoid recombination reactions, and maximize extraction of the neutral dye. Taking these theoretical observations into account, all of the experiments outlined below were carried out in emulsified biphasic systems achieved through vigorous stirring.

An additional parameter not considered in this study is the relative flow rates of the two solutions. This parameter could also be adjusted to optimize the extraction process, and also countercurrent flow could be investigated. Our study indicates that higher concentrations of neutral dye in the organic phase could be achieved by slowing down the flow of the organic phase, with only slight changes of the conversion of photons to product, as the extraction is already diffusion controlled.
Table 3. Effects of the Initial Concentration of the Dye in the Aqueous Phase and the Partition Coefficient for the Extraction Efficiency of HTh (Flux of HTh at the Outlet of the Organic Phase/Total Flux of HTh at the Outlet) and the Efficiency for the Conversion of Photons into HTh in the Oil Phase (Flux of HTh at the Outlet of the Organic Phase/Flux of Photons)

\begin{tabular}{ccc} 
& extraction efficiency (\%) & photon to product (\%) \\
$\mathcal{c}_{\mathrm{Th}+} / \mathrm{mM}\left(K_{\mathrm{p}}=10\right)$ & & \\
1 & 8.5 & 3.2 \\
10 & 50.2 & 20.5 \\
30 & 78.8 & 34.4 \\
50 & 85.7 & 39.5 \\
100 & 90.6 & 44.5 \\
500 & 93.7 & 53.1 \\
$K_{\mathrm{p}}\left(c_{\mathrm{Th}+}=30 \mathrm{mM}\right)$ & & \\
1 & 45.8 & 15.0 \\
2 & 59.7 & 21.7 \\
10 & 78.8 & 34.4 \\
100 & 84.9 & 39.9 \\
1000 & 85.6 & 40.6 \\
\hline
\end{tabular}

All in all, it is very interesting to see that large photon to product efficiencies can be achieved and that photoionic cells can be highly effective toward the production of "redox fuels".

4.2. Polarized Liquid-Liquid Interfaces. The use of a polarizable soft interface allows us to control the distribution of ions between both phases. Indeed, the concentration ratio is linked to the Galvani potential difference between the two phases $\left(\Delta_{\mathrm{o}}^{\mathrm{w}} \phi=\phi^{\mathrm{w}}-\phi^{\mathrm{o}}\right)$ by the Nernst equation: ${ }^{21}$

$$
\Delta_{\mathrm{o}}^{\mathrm{w}} \phi=\Delta_{\mathrm{o}}^{\mathrm{w}} \phi_{i}^{\ominus}+\frac{R T}{z_{i} F} \ln \left(\frac{a_{i}^{\mathrm{o}}}{a_{i}^{\mathrm{w}}}\right)
$$

which allows definition of the distribution of ions as a function of potential as:

$$
\begin{aligned}
P_{i} & =\frac{a_{i}^{\mathrm{o}}}{a_{i}^{\mathrm{w}}} \\
& =\exp \left[\frac{z_{i} F}{R T}\left(\Delta_{\mathrm{o}}^{\mathrm{w}} \phi-\Delta_{\mathrm{o}}^{\mathrm{w}} \phi_{i}^{\ominus}\right)\right] \\
& =P_{i}^{\ominus} \exp \left[\frac{z_{i} F}{R T} \Delta_{\mathrm{o}}^{\mathrm{w}} \phi\right]
\end{aligned}
$$

If the Galvani potential difference between the aqueous and oil phase is more negative than the standard transfer potential of the cations, $i$, most of the cations are in the aqueous phase.

The Nernst equation also has another interpretation: the Galvani potential difference across the liquid-liquid interface is controlled by the distribution of all the species across the interface. By adding equal amounts of a common ion into both phases, in excess compared to other ionic species (for example $100 \mathrm{mM}$ TBACl in the aqueous phase and $100 \mathrm{mM} \mathrm{TBAPF}_{6}$ in the oil phase), the Galvani potential difference is governed by this common ion and is equal to the formal potential of the ion. Of course, the Nernst equation for all the ions has to be satisfied as well as the electroneutrality of both phases. For the case of 100 $\mathrm{mM} \mathrm{TBACl}$ in the aqueous phase and $100 \mathrm{mM} \mathrm{TBAPF}_{6}$ in the oil phase, the equilibrium concentrations for equal volumes of the aqueous and DCE phases is given in Table 4, and the calculated Galvani potential difference was $-0.225 \mathrm{~V}$, exactly the standard potential for $\mathrm{TBA}^{+}$transfer reported in ref 32 . The calculation 
Table 4. Calculated Equilibrium Concentrations (mM) between $100 \mathrm{mM} \mathrm{TBAPF}_{6}$ in DCE and $100 \mathrm{mM} \mathrm{TBACl}$ in Water

\begin{tabular}{|ccc} 
& concentration in water $(\mathrm{mM})$ & concentration in DCE $(\mathrm{mM})$ \\
$\mathrm{TBA}^{+}$ & 100.24 & 99.76 \\
$\mathrm{PF}_{6}{ }^{-}$ & 0.24 & 99.76 \\
$\mathrm{Cl}^{-}$ & 100.00 & $7.10 \times 10^{-4}$ \\
\hline
\end{tabular}

details are given in the SI and have been described in detail by Hung. $^{38}$

In an ideal photoionic cell, $\mathrm{Th}^{+},[\mathrm{Co}(\mathrm{II}) \mathrm{EDTA}]^{2-}$, and $[\mathrm{Co}(\mathrm{III}) \mathrm{EDTA}]^{-}$should all remain in the aqueous phase. Hence, the transfer of $\mathrm{Th}^{+}$into the DCE phase was investigated by ion transfer voltammetry in a custom-made four-electrode cell, see Figure 3. In the absence of $\mathrm{ThCl}$, the potential window is

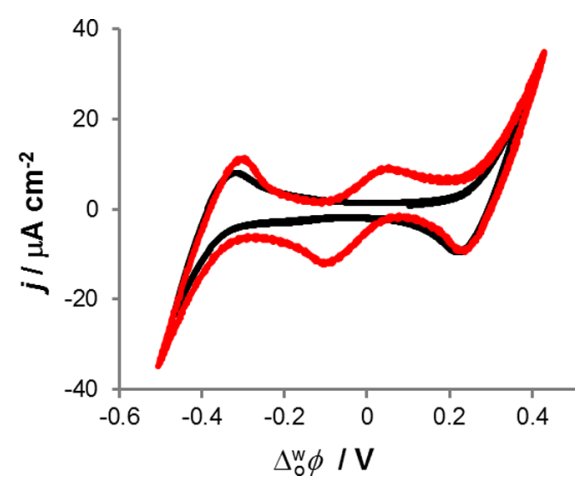

Figure 3. Ion transfer voltammograms in the absence (black line) and presence (red line) of saturated $\mathrm{ThCl}$ in the aqueous phase. See Scheme $3 \mathrm{~A}$ for the composition of the biphasic electrochemical cell. The scan rate was $50 \mathrm{mV} \mathrm{s}^{-1}$.

limited by the transfer of sodium at the positive end of the polarizable potential window and of phosphate species (either $\mathrm{PO}_{4}{ }^{3-}, \mathrm{HPO}_{4}{ }^{2-}$, or $\mathrm{H}_{2} \mathrm{PO}_{4}{ }^{-}$) at the negative end. When $\mathrm{Th}^{+}$is added, a reversible ion transfer at $-0.02 \mathrm{~V}$, corresponding to transfer of $\mathrm{Th}^{+}$, is observed. Similar results have been obtained earlier. $^{39}$

When either $[\mathrm{Co}(\mathrm{II}) \mathrm{EDTA}]^{2-}$ or $[\mathrm{Co}(\mathrm{III}) \mathrm{EDTA}]^{-}$were added, no additional waves were observed within the potential window as these complexes are highly hydrophilic, and hence their transfer takes place beyond or close to potentials of phosphate anion transfer. As previously mentioned, in the current system it is desirable to keep $\mathrm{Th}^{+}$and both cobalt complexes in the aqueous phase. On the basis of the information extracted from the ion transfer voltammograms, this can be accomplished by polarizing the liquid-liquid interface negatively at an intermediate potential between those for the transfer of $\mathrm{Th}^{+}$ and of both anionic Co complexes. An ideal species that fulfills this constraint are tetrabutylammonium cations $\left(\mathrm{TBA}^{+}\right)$. Thus, addition of $\mathrm{TBACl}$ to the aqueous phase and $\mathrm{TBAPF}_{6}$ to the DCE phase will set the potential at the interface close to the standard ion-transfer potential of $\mathrm{TBA}^{+}$at $-0.225 \mathrm{~V}$.

4.3. Spectroelectrochemistry. To better characterize the system under study, we revisited some additional aspects of the redox reactions, such as the reduction of $\mathrm{Th}^{+}$at neutral $\mathrm{pH}$. Cyclic voltammograms showed only one reversible wave for the reduction of $\mathrm{Th}^{+}$at ca. $-0.14 \mathrm{~V}$ vs $\mathrm{Ag} / \mathrm{AgCl}$. As shown in Figure 4 , spectral monitoring of the electrochemical reduction of $\mathrm{Th}^{+}$ using an optically transparent thin layer electrode (OTTLE)

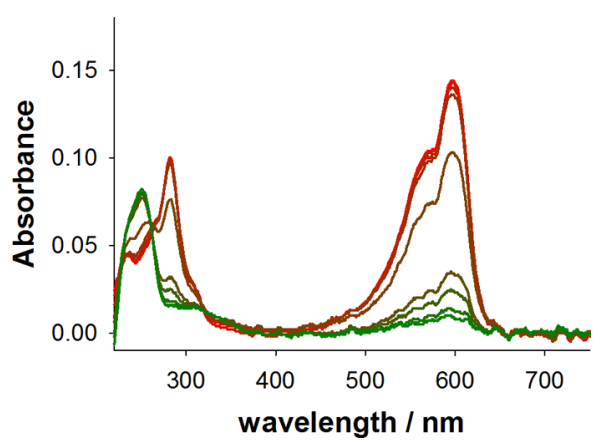

Figure 4. UV-visible spectra acquired as a function of potential from 0 to $-0.27 \mathrm{~V} \mathrm{vs} \mathrm{Ag} / \mathrm{AgCl}(3 \mathrm{M} \mathrm{KCl}$ ) (red to green spectra) for a solution of $0.022 \mathrm{mM}$ ThCl in $50 \mathrm{mM}$ phosphate buffer $(\mathrm{pH}=7.2)$. The potential step was $30 \mathrm{mV}$. The working, counter, and reference electrodes were $\mathrm{Pt}$ mesh, $\mathrm{Pt}$ wire, and $\mathrm{Ag} / \mathrm{AgCl}(3 \mathrm{M} \mathrm{KCl})$, respectively.

confirmed that under these experimental conditions, HTh is directly produced as evidenced by the presence of an isosbestic point at $265 \mathrm{~nm}$ accompanied by the increase in absorbance below $260 \mathrm{~nm}$ and the disappearance of the band at $597 \mathrm{~nm}$. These results are in agreement with the previously reported fast disproportionation mechanism of the one-electron reduction product, semithionine, to give $\mathrm{HTh}$ and $\mathrm{Th}^{+}{ }^{+33}$

As evidenced by the theoretical analysis above, a crucial parameter for the operation of a photoionic cell is the partition coefficient $K_{\mathrm{p}}$ of the reduced neutral dye between the two phases. To determine this equilibrium constant, $\mathrm{HTh}$ was produced via a potential-controlled electrolysis at $-0.45 \mathrm{~V}$ vs $\mathrm{Ag} / \mathrm{AgCl}$ (satd. $\mathrm{KCl}$ ) at $\mathrm{pH} 7.2$ and extracted into DCE. The spectrum obtained after the controlled potential electrolysis was consistent with that observed in spectroelectrochemical measurements. Using the data in Figure 5, the partition coefficient between water and DCE for $\mathrm{HTh}\left(K_{\mathrm{P}}^{\mathrm{W} / \mathrm{DCE}}\right)$ is calculated from the differences in absorbance at $249 \mathrm{~nm}$ of the aqueous phase before $\left(A_{249 \mathrm{~nm}}\left(t_{0}\right)\right)$ and after $\left(A_{249 \mathrm{~nm}}\left(t_{\text {final }}\right)\right)$ extraction with DCE. Taking into account that the water/DCE volume ratio $\left(V_{\mathrm{w}} /\right.$ $\left.V_{\mathrm{DCE}}\right)$ is equal to $2, K_{\mathrm{P}}^{\mathrm{W} / \mathrm{DCE}}$ was estimated to be:

$$
\begin{aligned}
K_{\mathrm{P}}^{\mathrm{W} / \mathrm{DCE}} & =\frac{[\mathrm{HTh}]_{\mathrm{DCE}}}{[\mathrm{HTh}]_{\mathrm{W}}} \\
& =\frac{A_{249 \mathrm{~nm}}\left(t_{0}\right)-A_{249 \mathrm{~nm}}\left(t_{\text {final }}\right)}{A_{249 \mathrm{~nm}}\left(t_{\text {final }}\right)} \frac{V_{\mathrm{W}}}{V_{\mathrm{DCE}}} \\
& =14.6
\end{aligned}
$$

4.4. Photoionic Cell. In the case of photoionic cells, the separation efficiency of the photoproducts can be easily determined by monitoring the absorbance of the aqueous phase at $597 \mathrm{~nm}$ before $\left(A_{597 \mathrm{~nm}}\left(t_{0}\right)\right)$ and after $\left(A_{597 \mathrm{~nm}}\left(t_{\text {final }}\right)\right)$ irradiation:

$$
\text { separation efficiency }=\frac{A_{597 \mathrm{~nm}}\left(t_{0}\right)-A_{597 \mathrm{~nm}}\left(t_{\text {final }}\right)}{A_{597 \mathrm{~nm}}\left(t_{0}\right)} \times 100
$$

The decrease of $\mathrm{Th}^{+}$in the aqueous phase after irradiation with a high power LED at $536 \mathrm{~nm}$ gives a separation efficiency of $76 \%$ (Figure 6a). The spectrum for the DCE phase after irradiation is presented in $6 \mathrm{~b}$. The peak at ca. $480 \mathrm{~nm}$ corresponds to $[\mathrm{Co}(\mathrm{II}) \mathrm{EDTA}]^{2-}$. When the same experiment was repeated with $100 \mathrm{mM} \mathrm{TBAPF}_{6}$ in DCE phase and $100 \mathrm{mM} \mathrm{TBACl}$ in the aqueous phase to prevent the transfer of $\mathrm{Th}^{+}$or CoEDTA species 

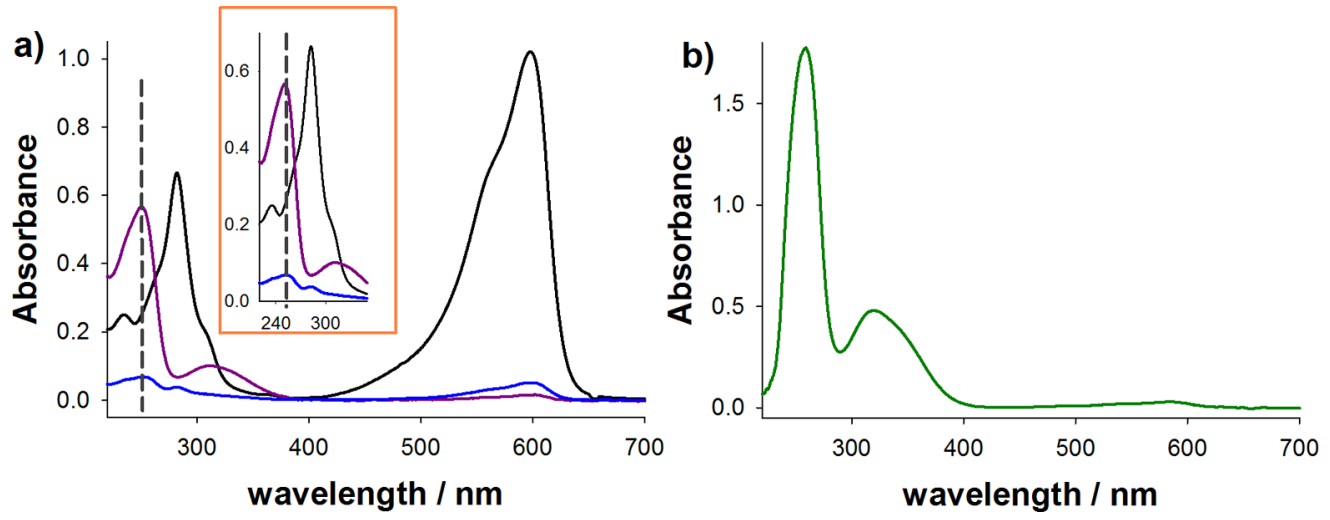

Figure 5. Determination of the partition coefficient $\left(K_{\mathrm{P}}^{\mathrm{W} / \mathrm{DCE}}\right)$ of the neutral dye (HTh) between the water and DCE phases. UV-visible spectra of (a) 5fold diluted aqueous phases containing $0.078 \mathrm{mM} \mathrm{ThCl}$ before (black) and after (violet) bulk electrolysis at $-0.45 \mathrm{~V}$ vs $\mathrm{Ag} / \mathrm{AgCl}$ and after (blue) extraction of HTh into DCE. A spectrum of the organic phase (diluted 2-fold) taken after extraction of HTh is presented in (b).
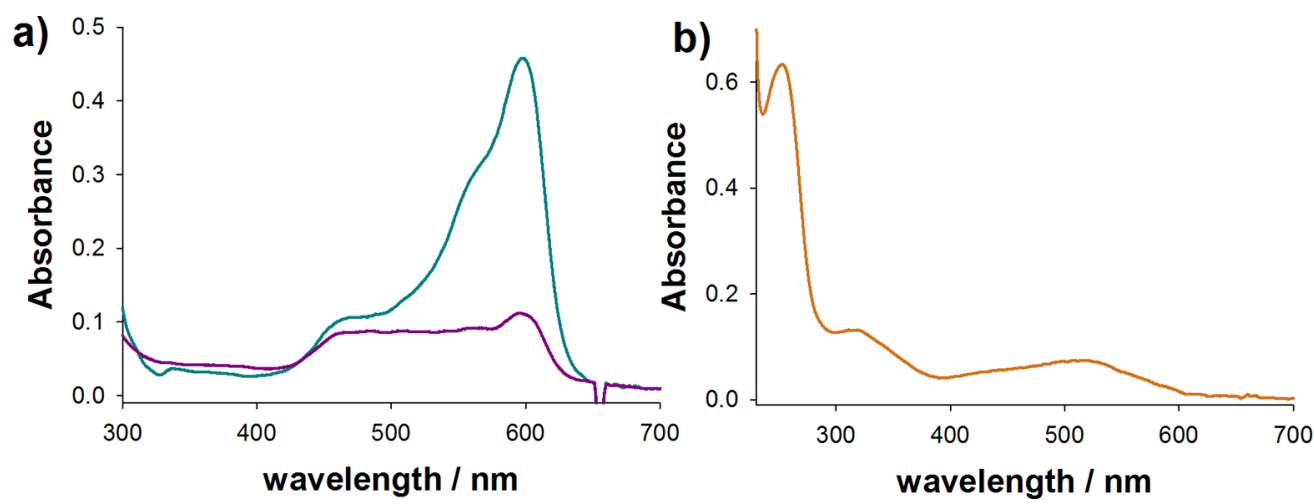

Figure 6. Monitoring the separation efficiency of the photoproducts (HTh and [Co(III)EDTA $]^{-}$) after irradiating the biphasic cell initially containing aqueous solubilized $\mathrm{Th}^{+}$and $[\mathrm{Co}(\mathrm{II}) \mathrm{EDTA}]^{2-}$ at $536 \mathrm{~nm}$ for $120 \mathrm{~min}$. The electrochemical cell configuration for the biphasic system before illumination is illustrated in Scheme 3B $(x=0, y=0, z=0.035)$. (a) UV-visible spectra of a 5-fold diluted aqueous phase before (blue) and after (violet) irradiation. The peaks at 480 and $597 \mathrm{~nm}$ in the aqueous phase correspond to [Co(II)EDTA $]^{2-}$ and $\mathrm{Th}^{+}$, respectively. (b) The spectrum for the DCE phase after irradiation is presented. The peaks at 255 and $316 \mathrm{~nm}$ correspond to HTh, and that at $519 \mathrm{~nm}$ corresponds to [Co(III)EDTA] ${ }^{-}$.
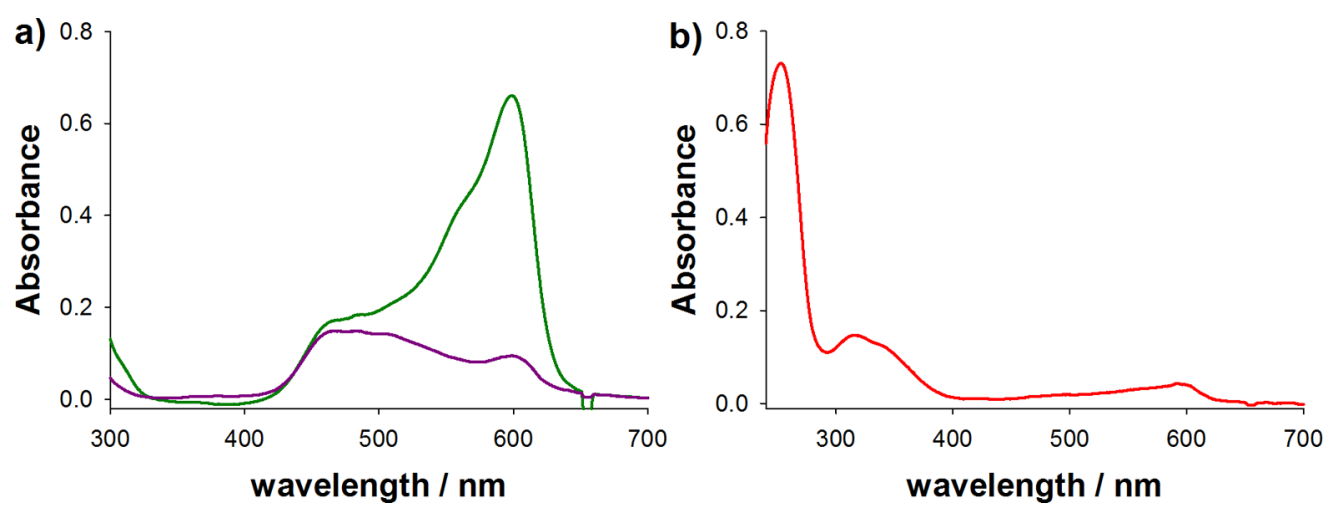

Figure 7. Observing the effect of polarizing the interface, with $\mathrm{TBA}^{+}$as a common ion in both phases, on the separation efficiency of the photoproducts $\left(\mathrm{HTh}\right.$ and $[\mathrm{Co}(\mathrm{III}) \mathrm{EDTA}]^{-}$) after irradiating the biphasic cell at $536 \mathrm{~nm}$ for $70 \mathrm{~min}$. The electrochemical cell configuration for the biphasic system before illumination is illustrated in Scheme 3B $(x=100, y=100, z=0.051)$. (a) UV-visible spectra of a 5-fold diluted aqueous phase before (green) and after (violet) irradiation. (b) The spectrum for the DCE phase after irradiation is presented, note the absence of the [Co(III)EDTA] ${ }^{-}$(present at 519 $\mathrm{nm}$ in Figure 6). All other peaks in the aqueous and organic phases are as described in Figure 6

into the DCE phase, as discussed in Section 4.2, an improved extraction efficiency of $85 \%$ was obtained, as shown by the UVvis spectra in Figure 7.

Besides the improvement in the separation efficiency observed when $\mathrm{TBA}^{+}$is present as a common ion in both phases, the band at $516 \mathrm{~nm}$ does not appear when the interface is polarized. The importance of this is that $[\mathrm{Co}(\mathrm{III}) \mathrm{EDTA}]^{-}$is not extracted into the organic phase and therefore, higher separation efficiencies can be obtained because the back-reaction is prevented in the organic phase. Also, addition of $\mathrm{TBACl}$ into the aqueous phase increased the solubility of $\mathrm{Th}^{+}$into the aqueous phase from 0.035 to $0.051 \mathrm{mM}$.

Initial attempts to determine the efficiency of the reaction with respect to the number of photons in an emulsified system were 
carried out with a laser at $543.5 \mathrm{~nm}$ at different time lapses. Nonetheless, complications arising from significant light scattering and light absorption by $[\mathrm{Co}(\mathrm{II}) \mathrm{EDTA}]^{2-}$ at $543 \mathrm{~nm}$ did not allow for an accurate determination of the number of absorbed photons by $\mathrm{Th}^{+}$(see $\mathrm{SI}$ ).

4.5. Electrochemical Discharge. Although in this work we do not address the intricacies of a biphasic redox flow cell, we performed discharge experiments to demonstrate the capability of photoionic cells to store charge and produce electricity on demand as required. For this purpose, we simply put the two immiscible phases collected under an inert atmosphere from an operational photoionic cell in contact with one another and placed a platinum wire in each phase. Specifically, the short circuit discharge of a photoionic cell, the cell configuration of which is illustrated in Scheme 3C, where both phases were obtained after $70 \mathrm{~min}$ of irradiation at $536 \mathrm{~nm}$ is shown in Figure 8 . For comparison, the discharge behavior of a fully charged cell

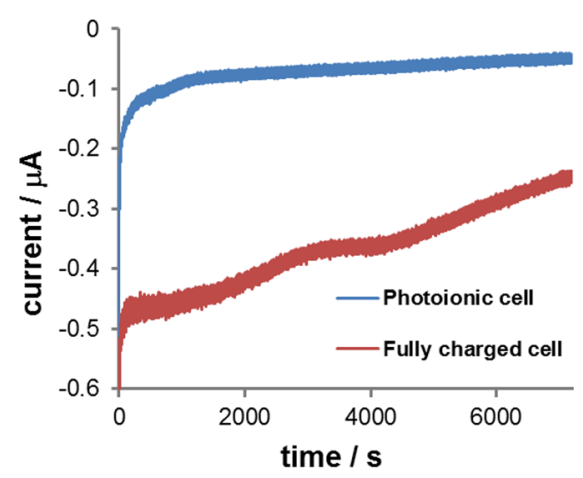

Figure 8. Discharge curves at the liquid-liquid interface for a photoionic cell charged by an LED light $\left(\lambda_{\max }=536 \mathrm{~nm}\right.$, see Scheme $3 \mathrm{C}$ for the electrochemical cell configuration) and, for comparison, the discharge of a cell prepared chemically (see Scheme 3D for the electrochemical cell configuration). In Scheme 3D, HTh was obtained by bulk electrolysis followed by extraction and [Co(III)EDTA $]^{-}$was synthesized chemically and dissolved in the aqueous phase.

prepared chemically, the cell configuration of which is illustrated in Scheme 3D, is presented in red in Figure 8. Again, this discharge experiment was performed in a cell with two Pt wires. Both cells displayed an open circuit potential of ca. $180-220 \mathrm{mV}$.

Control experiments of blank cells with only supporting electrolytes in both phases gave closed circuit currents of $8 \mathrm{nA}$, and a blank cell with $\mathrm{Th}^{+}$and $[\mathrm{Co}(\mathrm{II}) \mathrm{EDTA}]^{2-}$ in the aqueous phase gave currents of $6 \mathrm{nA}$. Hence, we conclude that the currents shown in Figure 8 stem from the discharge of the photoionic cell. When a fully charged cell, prepared chemically rather than in the photoionic cell, was left to discharge completely in a closed circuit over a two-day time lapse, all the $\mathrm{HTh}$ was converted back into $\mathrm{Th}^{+}$in the aqueous phase, as seen from Figure 9. The characteristic peak of HTh at $320 \mathrm{~nm}$ disappeared completely after discharge, and the peak at $597 \mathrm{~nm}$ for $\mathrm{Th}^{+}$was distinguished more easily after discharge by subtracting the spectra of $10 \mathrm{mM}[\mathrm{Co}(\mathrm{III}) \mathrm{EDTA}]^{-}$. This background correction was justified, as the concentration of Co(III) only slightly changed during discharge. Additionally, a broad peak at ca. $480 \mathrm{~nm}$ was observed in the organic phase, corresponding to $[\mathrm{Co}(\mathrm{II}) \mathrm{EDTA}]^{2-}$.

\section{CONCLUSION}

The goal of this study was to quantify the conversion efficiency of photoionic cells using the original $\mathrm{Th}^{+}-$cobalt EDTA system introduced by Rabinowitch et al. ${ }^{17}$

Finite element simulations were carried out to evaluate the influence of the different parameters. They clearly show that for a photoionic cell to be efficient the following criteria should be fulfilled:

- large excited state lifetime

- large partition coefficient of leucothionine $\left(K_{\mathrm{p}}\right)$

- large surface to volume ratio

- reasonable dye concentration

- large redox potential difference

For the current $\mathrm{Th}^{+}-[\mathrm{Co}(\mathrm{II}) \mathrm{EDTA}]^{2-}$ system, the large excited state lifetime is achieved, and a partition coefficient of ca. 15 is reasonably high. Among the main challenges to improve the efficiency are the solubility of $\mathrm{Th}^{+}$in the aqueous phase and the potential difference of only ca. $0.32 \mathrm{~V}$ between the redox couples. The solubility of $\mathrm{Th}^{+}$can be increased up to $30 \mathrm{mM}$ for example by introducing sulfonated groups into $\mathrm{Th}^{+}{ }^{40}$ Alternatively, a suspension of $\mathrm{Th}^{+}$aggregates could be used. Kamat et al. showed that $\mathrm{Th}^{+}$aggregates absorbing light at lower wavelengths could transfer energy to the $\mathrm{Th}^{+}$monomers in solution. ${ }^{41}$ Hence the use of aggregates should increase the light harvesting capability and the efficiency of the photoionic cells. To increase the cell voltage, redox species with higher redox potential than CoEDTA should be used, and there are many promising candidates available. However, increasing the redox potential also increases
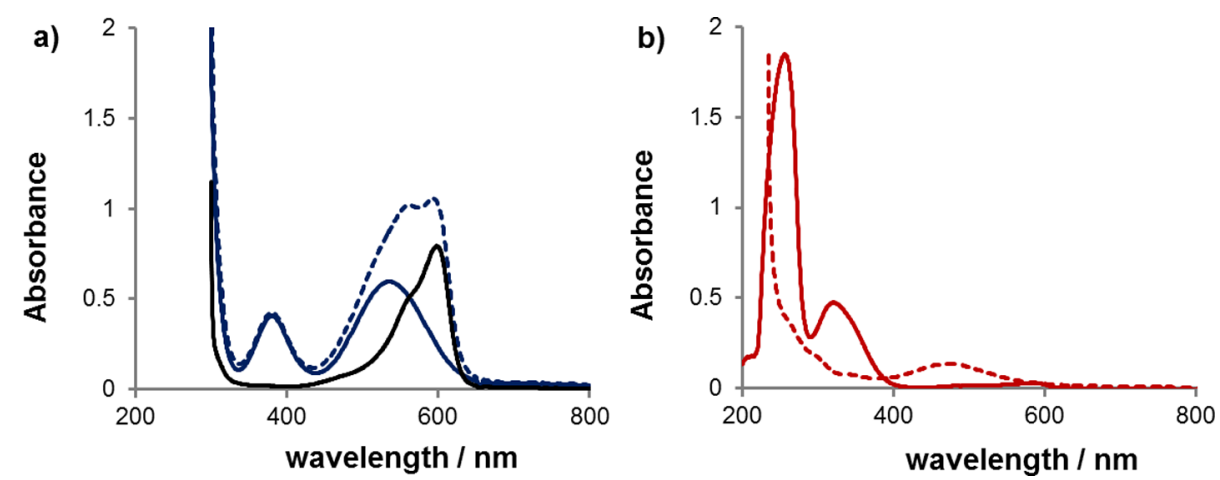

Figure 9. A cell prepared with $[\mathrm{Co}(\mathrm{III}) \mathrm{EDTA}]^{-}$initially present in the aqueous phase and HTh present in DCE (see Scheme 3D for the electrochemical cell configuration) was exhaustively discharged. (a) UV-vis spectra of the aqueous phase before (dark blue) and after (dashed blue) complete discharge. Background correction of the aqueous phase after discharge was performed as outlined in the text (black). The aqueous phase was diluted five times. (b) The corresponding spectra of the DCE phase before (red) and after (dashed red) discharge. 
the driving force of the recombination reaction, so compromises will have to be made.

Experiments were also carried out, and we have shown that by controlling the electrochemical aspects of the liquid-liquid interfaces $86 \%$ of the reduced dye could be extracted in a biphasic system under stirring. The next step of this work is to test the extraction efficiency under flow conditions.

A very preliminary study of the electrochemical discharge of the redox fuels has validated the concept, and the next step is to design a biphasic flow cell to generate electricity with an efficiency approaching that of classical redox flow batteries, i.e., $70-80 \%$.

\section{ASSOCIATED CONTENT}

\section{S Supporting Information}

Validation of the finite element method, model for the light absorption, photoreaction and extraction, and calculation of the Galvani potential difference across the liquid-liquid interface, preliminary determination of the quantum yield of the reaction and COMSOL model reports for $1 \mathrm{D}$ and $2 \mathrm{D}$ geometries are also included. This material is available free of charge via the Internet at http://pubs.acs.org.

\section{AUTHOR INFORMATION}

\section{Corresponding Author}

*E-mail: hubert.girault@epfl.ch. Phone: +41 216933151.

\section{Author Contributions}

The manuscript was written through contributions of all authors. All authors have given approval to the final version of the manuscript. M.A.M. and P.P. contributed equally to this work.

\section{Notes}

The authors declare no competing financial interest. M.A.M., manuel.mendezagudelo@epfl.ch; P.P., pekka.peljo@ epfl.ch; M.D.S.,micheal.scanlon@epfl.ch; H.V., heron.vrubel@ epfl.ch; H.H.G., hubert.girault@epfl.ch.

\section{ACKNOWLEDGMENTS}

The authors are grateful to Prof. Prashant Kamat (University of Notre Dame, IN) for the suggestion to revisit the original work of Rabinowitch and for fruitful discussions. H.H.G. thanks Michael Grätzel who has been a wonderful colleague during the last 20 years and wishes him a very happy 70th birthday. This work is supported by the Ecole Polytechnique Fédérale de Lausanne.

\section{ABBREVIATIONS USED}

$\mathrm{BA}^{+}$, bis(triphenylphosphoranylidene) ammonium cation; $\mathrm{CE}$, counter electrode; DCE, 1,2-dichloroethane; DSSC, dye sensitized solar cell; EDTA, ethylenediaminetetraacetate; ITIES, interface between two immiscible electrolyte solutions; $\mathrm{RE}$, reference electrode; SHE, standard hydrogen electrode; $\mathrm{TB}^{-}$, tetrakis(pentafluorophenyl)borate anion; $\mathrm{TBA}^{+}$, tetrabutylammonium cation; $\mathrm{Th}^{+}$, thionine cation; $\mathrm{TMA}^{+}$, tetramethylammonium cation; WE, working electrode

\section{REFERENCES}

(1) Shockley, W.; Queisser, H.J. Detailed Balance Limit of Efficiency of p-n Junction Solar Cells. J. Appl. Phys. 1961, 32, 510-519.

(2) Gratzel, M. Photoelectrochemical Cells. Nature 2001, 414, 338344.

(3) O’Regan, B.; Gratzel, M. A Low-Cost, High-Efficiency Solar Cell Based on Dye-Sensitized Colloidal TiO2 Films. Nature 1991, 353, 737740 .
(4) Burschka, J.; Pellet, N.; Moon, S.-J.; Humphry-Baker, R.; Gao, P.; Nazeeruddin, M. K.; Gratzel, M. Sequential Deposition as a Route to High-Performance Perovskite-Sensitized Solar Cells. Nature 2013, 499, 316-319.

(5) Abdin, Z.; Alim, M. A.; Saidur, R.; Islam, M. R.; Rashmi, W.; Mekhilef, S.; Wadi, A. Solar Energy Harvesting with the Application of Nanotechnology. Renewable Sustainable Energy Rev. 2013, 26, 837-852.

(6) Albery, W. J. Development of Photogalvanic Cells for Solar Energy Conservation. Acc. Chem. Res. 1982, 15, 142-148.

(7) Jana, A. K. Solar Cells Based on Dyes. J. Photochem. Photobiol., A 2000, 132, 1-17.

(8) Albery, W. J.; Archer, M. D. Optimum Efficiency of Photogalvanic Cells for Solar Energy Conversion. Nature 1977, 270, 399-402.

(9) Rabinowitch, E. The Photogalvanic Effect II. The Photogalvanic Properties of the Thionine-Iron System. J. Chem. Phys. 1940, 8, 560566.

(10) Rabinowitch, E. The Photogalvanic Effect I. The Photochemical Properties of the Thionine-Iron System. J. Chem. Phys. 1940, 8, 551559.

(11) Kamat, P. V.; Karkhanavala, M. D.; Moorthy, P. N. Kinetics of Photobleaching Recovery in the Iron(II)-Thionine System. J. Phys. Chem. 1981, 85, 810-813.

(12) Kamat, P. V. Photoelectrochemistry in Colloidal Systems: Interfacial Electron Transfer Between Colloidal $\mathrm{TiO}_{2}$ and Thionine in Acetonitrile. J. Photochem. 1985, 28, 513-524.

(13) Kamat, P. V. Photoelectrochemistry in Colloidal Systems. J. Chem. Soc., Faraday Trans. 1985, 81, 509-518.

(14) Mackay, R. A.; Grätzel, M. The Photoreduction of Thionine and Surfactant Thionine by Iron(II) in Anionic Micelles and Microemulsions. Ber. Bunsen-Ges. Phys. Chem. 1985, 89, 526-530.

(15) Grätzel, M. Artificial Photosynthesis, Energy and Light-Driven Electron Transfer in Organized Molecular Assemblies and Colloidal Semiconductors. Biochim. Biophys. Acta 1982, 683, 221-244.

(16) Mathai, K. G.; Rabinowitch, E. Studies of the Thionine-Ferrous Iron Reaction in a Heterogeneous System. J. Phys. Chem. 1962, 66, 663664.

(17) Srinivasan, V.; Rabinowitch, E. Photochemical Reduction of Thionine by Cobalt (II) EDTA Complex in Water-Ether Emulsion. J. Chem. Phys. 1970, 52, 1165-1168.

(18) Kotov, N. A.; Kuzmin, M. G. A Photoelectrochemical Effect at the Interface of Immiscible Electrolyte Solutions. J. Electroanal. Chem. 1990, 285, 223-240.

(19) Kotov, N. A.; Kuzmin, M. G. Nature of the Processes of ChargeCarrier Generation at ITIES by the Photoexcitation of Porphyrins. J. Electroanal. Chem. 1992, 338, 99-124.

(20) Kuzmin, M. G.; Soboleva, I. V.; Kotov, N. A. Kinetics of Photoinduced Charge Transfer at Microscopic and Macroscopic Interfaces. Anal. Sci. 1999, 15, 3-16.

(21) Peljo, P.; Girault, H. H. In Encyclopedia of Analytical Chemistry; John Wiley \& Sons, Ltd: New York, 2012.

(22) Fermín, D. J.; Ding, Z.; Duong, H. D.; Brevet, P.-F.; Girault, H. H. Photoinduced Electron Transfer at Liquid/Liquid Interfaces. 1. Photocurrent Measurements Associated with Heterogeneous Quenching of Zinc Porphyrins. J. Phys. Chem. B 1998, 102, 10334-10341.

(23) Fermin, D. J.; Duong, H. D.; Ding, Z.; Brevet, P.-F.; Girault, H. H. Photoinduced Electron Transfer at Liquid/Liquid Interfaces Part II. A Study of the Electron Transfer and Recombination Dynamics by Intensity Modulated Photocurrent Spectroscopy (IMPS). Phys. Chem. Chem. Phys. 1999, 1, 1461-1467.

(24) Eugster, N.; Fermín, D. J.; Girault, H. H. Photoinduced Electron Transfer at Liquid/Liquid Interfaces. Part VI. On the Thermodynamic Driving Force Dependence of the Phenomenological Electron-Transfer Rate Constant. J. Phys. Chem. B 2002, 106, 3428-3433.

(25) Su, B.; Eugster, N.; Girault, H. H. Reactivity of MonolayerProtected Gold Nanoclusters at Dye-Sensitized Liquid/Liquid Interfaces. J. Am. Chem. Soc. 2005, 127, 10760-10766.

(26) Fermín, D. J.; Duong, H. D.; Ding, Z.; Brevet, P. F.; Girault, H. H. Solar Energy Conversion Using Dye-Sensitised LiquidlLiquid Interfaces. Electrochem. Commun. 1999, 1, 29-32. 
(27) Halls, J. E.; Wadhawan, J. D. Photogalvanic Cells Based on Lyotropic Nanosystems: Towards the Use of Liquid Nanotechnology for Personalised Energy Sources. Energy Environ. Sci. 2012, 5, 65416551.

(28) Ogino, H.; Ogino, K. Redox Potentials and Related Parameters of Cobalt(III/II) Complexes Containing Aminopolycarboxylates. Inorg. Chem. 1983, 22, 2208-2211.

(29) Arning, M. D.; Minteer, S. D. In Handbook of Electrochemistry; Zoski, C. G., Ed.; Elsevier: Amsterdam, 2007, p 813-814.

(30) Dwyer, F. P.; Gyarfas, E. C.; Mellor, D. P. The Resolution and Racemization of Potassium Ethylenediaminetetra-Acetatocobaltate(III). J. Phys. Chem. 1955, 59, 296-297.

(31) Fermín, D. J.; Duong, H. D.; Ding, Z.; Brevet, P. F.; Girault, H. H. Photoinduced Electron Transfer at Liquid/Liquid Interfaces. Part II. A Study of the Electron Transfer and Recombination Dynamics by Intensity Modulated Photocurrent Spectroscopy (IMPS). Phys. Chem. Chem. Phys. 1999, 1, 1461-1467.

(32) Wandlowski, T.; Mareček, V.; Samec, Z. Galvani Potential Scales for Water-Nitrobenzene and Water-1,2-Dichloroethane Interfaces. Electrochim. Acta 1990, 35, 1173-1175.

(33) Ferreira, M. I. C.; Harriman, A. Photoredox Reactions of Thionine. J. Chem. Soc., Faraday Trans. 1977, 73, 1085-1092.

(34) Albery, W. J.; Archer, M. D. Photogalvanic Cells: Part 3. The Maximum Power Obtainable from a Thin Layer Photogalvanic Concentration Cell with Identical Electrodes. J. Electroanal. Chem. 1978, 86, 1-18.

(35) Hatchard, C. G.; Parker, C. A. The Photoreduction of Thionine by Ferrous Sulphate. Trans. Faraday Soc. 1961, 57, 1093-1106.

(36) Furukawa, K.; Takahashi, Y.; Sato, H. Effect of the Formation of EDTA Complexes on the Diffusion of Metal Ions in Water. Geochim. Cosmochim. Acta 2007, 71, 4416-4424.

(37) Hazafy, D.; Salvia, M.-V.; Mills, A.; Hutchings, M. G.; Evstigneev, M. P.; Parkinson, J. A. NMR Analysis of Nile Blue and Thionine in Solution. Dyes Pigm. 2011, 88, 315-325.

(38) Hung, L. Q. Electrochemical Properties of the Interface Between Two Immiscible Electrolyte Solutions Part I. Equilibrium Situation and Galvani Potential Difference. J. Electroanal. Chem. 1980, 115, 159-174.

(39) Iglesias, R. A.; Mora, M. F.; Baruzzi, A. M. Spectroelectrochemical Analysis of the Thionine Transfer Coupled to a Photoinduced Chemical Reaction Across the Water-1,2-Dichloroethane Interface. J. Electroanal. Chem. 2005, 585, 113-119.

(40) Albery, W. J.; Bartlett, P. N.; Foulds, A. W.; Souto-Bachiller, F. A.; Whiteside, R. Photogalvanic Cells. Part 14. The Synthesis and Characterization of Disulphonated Thionines. J. Chem. Soc., Perkin Trans. 2 1981, 794-800.

(41) Das, S.; Kamat, P. V. Can H-Aggregates Serve as Light-Harvesting Antennae? Triplet-Triplet Energy Transfer Between Excited Aggregates and Monomer Thionine in Aersol-OT Solutions. J. Phys. Chem. B 1998, 103, 209-215. 